\title{
PRENSA LOCAL Y RÉGIMEN AUTORITARIO: EL CASO DE LA FOLHA DE SÃO BORJA EN LOS AÑOS 70
}

\author{
Local Press and the authoritarian regime: Folha de São Borja's \\ case in the seventies
}

Imprensa local e regime autoritário: o caso da Folha de São Borja nos anos 70

Mara Regina Rodrigues

Ribeiro

Professora Dr ${ }^{a}$ em Ciências Sociais (UNIPAMPA)

mararibeiro@unipampa.edu.br

\section{Resumo}

O foco deste trabalho está organizado no sentido de discutir a imprensa local em períodos de autoritarismo, bem como seu papel e forma de atuação em cidades de fronteira. Articula a produção do jornal Folha de São Borja, iniciada nos anos 70, e as suas estratégias de legitimar o seu próprio discurso diante da atuação do governo de Emilio Garrastazú Médici e da ideologia nacional desenvolvimentista difundida pelo governo na época.

Palavras-chave: imprensa local; autoritarismo; legitimação.

\begin{abstract}
The focus of this piece organizes itself in the sense of discussing the local press during authoritarian periods, as well as its part and form of acting in frontier cities. It articulates the production of Folha de São Borja newspaper, which started publication in the seventies, and its strategies of legitimizing its own speech ahead of the government intervention of Emilio Garrastazú Médici and the expansionist national ideology widespread by the government at the time.
\end{abstract}

Key words: local press, authoritarianism; legitimation words.

\section{Resumen}

El foco de este trabajo está organizado a en el sentido de discutir la prensa local en periodos de autoritarismo, así como su papel y forma de actuación en ciudades de frontera. Articula la producción del periódico Folha de São Borja, iniciada los años 70, y sus estrategias de legitimar su propio discurso delante de la actuación del gobierno de Emilio Garrastazú Médici y de la ideología nacional desarrollista difundida por el gobierno en la época ${ }^{\mathrm{i}}$.

Palabras clave: prensa local, autoritarismo, legitimación. 


\section{INTRODUÇÃO}

Los estudios referentes a prensa local, centrados en las pequeñas ciudades fronterizas de Brasil, son escasos. No obstante, conforme indica Tétu (2002, p. 431), las cuestiones nacionales, los cambios y las crisis de la sociedad son, inicialmente, vividos en el ámbito local, donde la producción periodística se basa en la proximidad comunitaria, en la legitimación social y en el poder económico. Se destaca, sin embargo, el mérito de este tipo de empresa periodística por su presunta función comunitaria, pues forma parte de la vida de la ciudad al mostrar problemas, acontecimientos, reivindicaciones y otras cuestiones locales, pues se encuentra privilegiada, principalmente, por su proximidad con el público y los problemas locales. Considerando su función e importancia el cuestionamiento principal está centrado en el posicionamiento que esa prensa local asume en momentos emblemático de la sociedad cuando, por ejemplo, se implanta regímenes políticos de excepción. La discusión que se presenta en este artículo tiene cómo referencia dos puntos: el contexto histórico del régimen civil militar, empezado en Brasil a partir de 1964; y, la producción del periódico local Folha de São Borja, en los años en que Emilio Garrastazú Médici ocupó la presidencia de la República, en concreto entre 1970 hasta 1973. Médici fue el tercer gobernante del régimen militar en Brasil, cuyo mandato fue del 30 de octubre de 1969 hasta el 15 de marzo 1974.

Los periódicos impresos y los demás medios de comunicación intentan integrarse y crear una identificación con su público. Según Peter Berger e Thomas Luckmann (1999), la realidad de la vida cotidiana es más efectiva y se sobresale a la conciencia de una forma más intensa, porque es accesible a los miembros de la sociedad por el sentido común. Ella es interpretada y dotada de sentidos subjetivos, que ayudan a hacer el mundo más coherente.

Camponez (2002) indica que los periódicos locales, debido a que tienen una mirada peculiar sobre los problemas y las cuestiones próximas a los agentes, fueron responsables por debatir temas de interés público local, alertar y orientar las comunidades que constituyen una determinada región. La prensa local de la misma manera se relaciona con el desarrollo de esas región, en el caso de la Folha de São Borja es la frontera oeste del Río Grande del Sur. La región se caracteriza por presentar una estructura urbana dispersa con grandes vacíos demográficos y marcada por la ausencia de ciudades con gran desarrollo económico. Los municipios de Uruguaiana y Santana del Livramento, los más importantes, concentran juntos el 35,56 \% de la población de la región. El territorio también tiene seis ciudades medianas, cuatro pequeñas y seis aglomeraciones internacionales: tres situadas junto a frontera con la 
República Argentina: São Borja/Santo Tomé, Itaqui/General Alvear y Uruguaiana/Paso de Los Libres; dos con la República Oriental de Uruguay: Quaraí/Artigas y Santana del Livramento/Rivera; y una junto a Uruguay y Argentina: Barra del Quaraí/Bella Unión/Monte Caseros.

Las actividades económicas en la frontera con Uruguay son dominadas de un lado y de otro por la pecuaria extensiva y por el cultivo del arroz. En el territorio uruguayo se destacan, también, la explotación forestal, la fruticultura y la producción de leche. En la frontera con Argentina, la franja de territorio brasileño es, principalmente, el área más dinámica, con fuerte producción de granos y una agroindustria bien estructurada, con relevancia para el segmento de máquinas e implementos agrícolas. En la porción argentina, que comprende las provincias de Corrientes y Misiones, predomina la explotación forestal, apareciendo, también, la ganadería actividades de creación, aunque la producción total de carne de esas dos provincias sea poco relevante en la producción total del país. ${ }^{i i}$

Las grandes distancias entre los principales centros urbanos presentan como consecuencia un mercado consumidor relativamente pequeño y bastante discontinuo. En virtud de la predominancia de grandes propiedades rurales, la región presenta de más baja densidad demográfica del Estado, sólo 12 habitantes por km2, y la mayor concentración de tierras, vuelta, básicamente, para la pecuaria extensiva y la producción de arroz. La industria es poco relevante en el ámbito estadual, y los únicos sectores que se destacan son los relacionados al procesamiento de productos de origen vegetal y animal, más específicamente, los segmentos de abate de bovinos y beneficiamiento de productos como el arroz. La actividad pecuaria, aunque importante desde el punto de vista de las potencialidades de la región, presenta baja integración en la cadena, un rebaño heterogéneo y bajo índice de rastreabilidad del gado.

Además, destacase en el contexto político de la región en una perspectiva histórica a ciudad de São Borja por ser cuna de dos presidentes de la república brasileña: Getúlio Vargas, que cumplió dos mandatos en los períodos de 1930 a 1945 y 1951 a 1954; y João Goulart (Jango) de 1961 a 1964. La información mediatizada sobre la imagen pública de Goulart carga rasgos de las diferencias políticas que marcan la trayectoria del ex-presidente. Este ya tenía antes de la llegada de los militares al gobierno de la República trazos que lo diferenciaban de otros políticos derechistas. Él llega al poder tras la crisis electoral y política generada por la renuncia de Jânio Quadros, en los comienzos de la década de 60. Biroli (2006) destaca que las cuestiones en torno a la caracterización de Goulart como reformista, 
socialista, comunista, peronista, entre otras, son también importantes. Basta acordar que las justificaciones para el golpe de 1964 (considerando que sectores de la UDN y de las Fuerzas Armadas llevaron adelante tentativas de golpe al largo de las décadas de 50 y 60 antes de su consumación en 1964) tuvieron como uno de sus elementos la asociación de Jango a un plan de implementación del socialismo o del comunismo en Brasil, en base a un supuesto golpe apoyado por la URSS y por Cuba.

Goulart toma posesión como presidente en un sistema parlamentarista. La situación fue temporal, a través de un plebiscito el país vuelve al presidencialismo en 1963. Asumiendo el poder íntegralmente, Goulart retomó la tradición getulista con un programa nacionalista y reformista. En ese momento lanza el Plan Trienal, con el objetivo de contener la inflación y mantener el nivel de crecimiento económico. Aun así el escenario económico y político del país permanece inestable. Uno de los primeros sobresaltos está relacionado a las reformas de base defendidas por João Goulart, que tenían una fuerte connotación izquierdista y preveían cambios en la estructura económica y social del pais. Esa posibilidad provocó, por un lado, agitación entre las clases trabajadoras y los movimientos de campesinos y, por otro, preocupación entre los latifundistas y propietarios en forma generalizada.

En ese momento, nuevamente la izquierda sin unidad demuestra fragilidad para sostener al gobierno. Según Skidmore (1988, p. 42), el Partido Comunista Brasileño (PCB) aconsejaba al gobierno cautela, y el Partido Comunista de Brasil (PC de la B) exigía medidas radicales. Sin evaluar correctamente la situación, Goulart llega en 1964 con una fuerte oposición. Ese mismo año el gobierno queda insustentable, porque sus propuestas diferían de los intereses políticos y económicos presentes en el escenario brasileño desde 1950, conectados al capital extranjero, asociado al nacional, y al Estado propiamente dicho - derechista - y los militares. Juntos, bajo el pretexto de enfrentar la amenaza comunista y de restablecer la orden para la ejecución de reformas legales, se articula la toma del poder que se concretizó en $1^{\circ}$ de abril de 1964.

\section{CONTEXTO SOCIO HISTÓRICO DE PRODUCCIÓN DE LA FOLHA DE SÃO BORJA}

En las décadas de 60 y 70 en América latina y Brasil hubo un predominio de gobiernos políticos civil militares que para Collier (1982 son caracterizados por adoptar posturas autoritarias como, por ejemplo, control del proceso electoral, la intervención en los sindicatos 
de trabajadores y el patrocinio de políticas de austeridad económica. El autor señala que en ese período los países de la región vivieron sistemas políticos que tenían una acción no democrática, derivada de las tensiones de orden político-económico y social vivido en el Cono Sur, más específicamente en Brasil, Argentina, Uruguay, Chile.

También señala que el autoritarismo ocurrió en sociedades con un relativo desarrollo industrial, bajos niveles de institucionalidad política, y que pasaron por experiencias democratizadoras. Para el autor, a los fines de los años 1950, esas sociedades pasaban por procesos de intensa movilización de movimientos reivindicatorios, lo que posibilitó que los militares ocupasen el Estado, convirtiéndose así en los principales actores en el escenario político, "adotando um enfoque tecnocrático e burocrático na formulação política" (Collier, 1982, p.12).

Para Cardoso (1975, p. 19) los gobiernos de estos países se asentaron en políticas esencialmente desmovilizadoras, que utilizaban los recursos políticos del Estado y se firman en un contexto elitista. Sin embargo, el autor destaca que la burocracia estatal no explica todo, pues, de la misma forma, en el sector privado también se expande una gran valorización de los técnicos en el proceso de decisión e influencia en el proceso político.

Según O’Donnell (1986, p.17), en Brasil, específicamente después de 1964, el régimen se caracteriza por "uma relação de domínio que articula desigualmente a sociedade civil, resguardando e organizando a dominação nela exercida". Todavía, el grupo que asume el poder en el caso brasileño no representa directamente a la burguesía, aunque tenga esa clase como base social de apoyo. Lo que se acentúa es que la propuesta se fija en la exclusión del sector popular de las decisiones económicas, minimizando también su participación política. (O’DONNELL, 1986, p. 21). Los gobiernos militares no estaban vinculados a las clases populares y la mejoría de su calidad de vida, por el contrario su discurso exhibe de forma prioritaria la reorganización de la sociedad y el crecimiento económico.

O’Donnell (1986) y Cardoso (1975) estudian los sujetos involucrados en ese contexto y subrayan la formación de alianzas que garantizaron la adquisición de poder por los militares, que se apropian de la representación de un proyecto que alcanzaba a los intereses de la clase burguesa, que se sentía amenazada por el gobierno que buscaba el apoyo de los sectores populares - el gobierno del presidente João Goulart. En esta fase política en Brasil se gestó una situación de conflictos que se establecían a partir del aumento en la participación política de las masas, de la presunta amenaza del comunismo y la crisis económica interna. 
Después del derrocamiento del antiguo gobierno, los nuevos dirigentes presentaron su apoyo a grupos que buscaban ventajas frente a los cambios. Por lo tanto, el ciclo militar en Brasil representó una transferencia del poder político hacia los militares. La burguesía, entonces, abre espacio de decisión política apoyándolos y, como contraprestación, obtendría la recuperación gradual de sus inversiones y el mantenimiento del modelo capitalista.

Sin embargo, esclarece Cardoso (1975), "uma aliança entre classes ou frações de classes não significa eliminação dos interesses contraditórios" (CARDOSO, 1975, p. 128). Por ejemplo, mientras el gobierno obtiene el apoyo de Estados Unidos, que financió la recuperación económica del país, parte de ese grupo cuestiona el modelo de desarrollo a partir de la entrada de las empresas norteamericanas en el país. No obstante, los empresarios nacionales no abandonaron su apoyo al gobierno, pues el control de las masas populares y la congelación de los salarios garantizaban el mantenimiento de las ganancias y la conservación de las grandes empresas. Por otro lado, la clase media se beneficia con la ampliación de los puestos de trabajo asociados al arribo de las empresas extranjeras y de los empleos generados con la reformulación del Estado.

No obstante, la inserción de la economía brasileña en el sistema capitalista mundial dificulta la imposición y organización de directrices económicas nacionales, que se orienten a la acumulación interna, con inversiones en recursos humanos y materiales vinculados al mercado local. Eso se debe a que, a medida que aumentan las inversiones de capitales externos, los límites entre la burguesía nacional y la internacional son cada vez más borrosos. Inversiones del Estado tienden a ser organizadas para ofrecer infraestructura urbana a las grandes empresas multinacionales. Esas asumen una concepción de modernización donde el origen no está relacionado con el trabajo y con la riqueza nacional, sino con la importación, y la inversión externa inicial como propulsor del progreso.

\section{LA PRENSA LOCAL EN TÉRMINOS GENERALES Y A CARACTERIZACIÓN DE LA FOLHA DE SÃO BORJA}

Mouillaud (2002) apunta que el periódico diario se transformó en el substituto del espacio público y en él se articulan y se reproducen el discurso de la propia empresa periodística y de otros enunciadores, resonancia de diversas y diferentes voces públicas. Permeándolo, así, por varios discursos que se entrecruzan. 
El discurso, del otro o de la propia voz del periódico, está encerrado en dispositivos que consisten, según Mouillaud (2002, p. 34), en "os lugares materiais ou imateriais nos quais se inscrevem os textos (despachos de agências, jornais, livros, rádio, televisão)" y los textos son entendidos como "qualquer forma (de linguagem, icônica, sonora, gestual) de inscrição." Para el autor el dispositivo no es el soporte, sino una matriz que impone forma al texto. La relación entre texto y dispositivo es dinámica, pues uno genera el otro. La dinámica dispositivo/texto coloca en relieve la información, construye visibilidad y otorga profundidad y relevancia, o sea, "o que vêm a frente com relação a um fundo sem imagem [...]." (MOUILLAUD, 2002, p. 43).

Uno de los elementos que contribuye para la definición de que el acontecimiento común en la sociedad se transfigure en información está relacionado a los criterios de noticiabilidad. Más específicamente la proximidad de las noticias. Ese principio es destacado por la gran mayoría de los teóricos del área y hace referencia no sólo la cuestión geográfica noticias de ámbito nacional, regional o local, que demandan convivencia y cohabitación espacio-temporal; también se refiere a un factor de identificación que se genera con las temáticas de las noticias mediatizadas y la posibilidad de intercambio de las mismas con otros grupos. Alsina (1993) explica que emergen implicaciones afectivas y psicológicas entre los grupos al compartir el conocimiento común respeto de determinados temas.

Más aún, la mediación que se proporciona a partir del periodismo local, reorganiza la interacción social, en función de la proximidad de los agentes sociales y de su carácter comunitario. Correia (1998) y Dornelles (2010) señalan rasgos comunes para la prensa del interior que son: fuerte relacionamiento entre las élites locales y los medios de comunicación; más espacios para el artículo de opinión y para la colaboración externa; y una conexión acentuada entre el contenido de los artículos y las preocupaciones manifestadas en los espacios de reunión de los públicos, cierta ligación con los anuncios publicitarios y espacio para manifestaciones del lector.

La prensa en las ciudades del interior, en general, mantiene un fuerte carácter regional, constituyéndose en base de distinguidas voces en los discursos de las regiones brasileñas. Todavía no es efectivamente la situación de la producción de la Folha de São Borja, específicamente en sus primeros años de existencia. Según Dornelles (2010), la prensa del interior del Rio Grande do Sul se establece con bases sólidas entre finales del siglo XIX y mediados del XX. Es la primera y más representativa del país, igualándose con la de São Paulo, Minas Gerais y de Rio de Janeiro. El trabajo periodístico realizado en el interior en los 
comienzos de la prensa brasileña repercutió en lo que se hacía en ámbito estadual y nacional: una actividad desarrollada por idealistas, sin fines lucrativos, inicialmente partidaria, o sea, sin carácter informativo, e identificada por el género de opinión.

São Borja, ciudad en que se produce el periódico la Folha de São Borja, objeto de este estudio, tiene una prensa que sigue estos mismos patrones de forma general. Empieza en los finales del siglo XIX con dos periódicos semanales: Eco das Missões y el Movimento. La mayoría de estos emprendimientos tiene vida corta, reflejando la inestabilidad política y social, característica de un periodo caracterizado por diversas luchas. Es en el inicio de la década del siglo $\mathrm{XX}$ cuando surge el periódico Uruguay, el primero con periodicidad y constancia de más de 40 años. Estaba identificado con el partido Republicano y era de propiedad de la familia Vargas, grupo en el que se forma el político Getulio Vargas, que lidera la Revolución de 30 en Brasil y alcanza la presidencia de la República por dos mandatos.

Ya en los años 40, la ciudad contaba con una emisora de radio: Fronteira Sul, fundada por un grupo de empresarios, representantes de diferentes corrientes políticas que desarrollaban diversas actividades económicas. La Fronteira Su AM surge con un carácter idealista, porque los equipamientos eran precarios y las condiciones de transmisiones adversas (EMERIN \& PIPPI, 2007). Mantenía programas informativos, de deporte, con transmisiones de partidas de fútbol en Brasil y en Argentina, y programas de auditorio, acompañado por un conjunto musical de la propia emisora. A pesar de la programación y de la repercusión que la emisora poseía, en 1975 un representante de la Comisaría Nacional de Telecomunicaciones (Dentel) sin aviso previo o cualquier comunicado oficial, determinó el cierre de las transmisiones radiofónicas. Los motivos apuntados eran por participar en su cuadro de accionistas João Goulart, presidente que fue depuesto por la el gobierno militar en abril de 1964.

En este período la ciudad contó apenas con el periódico Folha de São Borja, fundada en febrero de 1970, por la Familia Grisolia, también propietaria del periódico A Noticia, de la ciudad de São Luiz Gonzaga. Con periodicidad semanal, en formato tabloide y con una media de 12 páginas, el mismo estaba dividido en cinco secciones principales: general, policía, deporte, publicaciones legales y columna social, a cargo de Zely Espindola. Además, tenía otra columna de Cultura que traía como responsables Tânia Siqueira y Claúdius; una de deportes, con Claudio Viero y también la nombrada "de minha janela", escrita por el poeta y escritor Apparício Silva Rillo, que tenía el apodo de Don Siri. El periódico tenía ventas en 
quioscos o por subscripción. En algunas ediciones es posible encontrar anuncios que indicaban los puntos de ventas y que incentivaban la realización de subscripciones.

La Folha de São Borja es uno de los varios ejemplos de empresa periodística local en Brasil, que a lo largo del siglo XX crecieron en cantidad y calidad. Lo mismo se pueden observar al analizar la historia de la prensa en Brasil, en que surgieron diversas iniciativas personales, motivadas por diferentes factores, generalmente apoyadas en una fuerte ideología político partidaria, en la cultura del profesional y de la sociedad donde él vive.

Además de eso, esa prensa formatea una malla de comunicación local-internacional de las tierras de frontera, como indica Machado (2008). Situada en la triple frontera BrasilUruguay-Argentina, la actual frontera oeste, surgió como descendiente americana de enfrentamientos peninsulares históricos entre las coronas ibéricas, especialmente en el periodo de finales del siglo XVII hasta el comienzo de siglo XIX. La misma corresponde al borde de frontera cuya progresiva dilatación, fruto de diversos tratados diplomáticos, culminó con la creación del estado-nación de Uruguay (1826), configurado en bufferzone entre el Imperio del Brasil y las Provincias Unidas del Río de la Plata, más tarde Argentina. Es por ello que hoy la mitad suroeste del Río Grande del Sur es conocida por la denominación de Frontera.

Culturalmente, las fronteras pueden ser entendidas como membranas a través de las cuales las personas, bienes e informaciones pueden circular, pudiendo ser o no aceptas por el Estado. Machado (2008) indica tres elementos constitutivos de la noción de frontera: la línea limítrofe, la cual simultáneamente permite separar y unir los estados-nación; las estructuras físicas del estado que buscan demarcar y proteger tal línea de frontera, compuesta de personas y estructuras enraizadas profundamente en el territorio nacional; y las zonas territoriales, cuyas variadas dimensiones se ensanchan a partir y a través de fronteras, dentro de las cuales las personas negocian una variedad de comportamientos y significados asociados a pertenezca a los y estados. La frontera brasileña está definida por la Ley n ${ }^{\circ}$ 6634, de 02 de mayo de 1979, la cual revocó la Ley n ${ }^{\circ}$ 2597, de 12 de septiembre de 1955, y también alteró el Decreto-ley $\mathrm{n}^{\circ} 1135$, de 03 de diciembre de 1970, poco tiempo después de iniciado el régimen militar.

\section{LA LEGITIMACIÓN EN TIEMPOS DE RÉGIMEN AUTORITARIO}

La producción del periódico Folha de São Borja empieza en los años 70, década que estaba señalada por cuestiones autoritarias en la conducción política administrativa del país. Después de la implementación del gobierno militar de 1964, hubo una modernización de la 
economía, sin embargo las estructuras sociales y la dependencia externa no fueron alteradas. El resultado sería un aumento de la dependencia tecnológica y estructural, visto la importancia creciente de las empresas multinacionales en el suministro de componentes industriales y bienes y servicios, junto a una dependencia financiera asociada al endeudamiento externo, que crece al largo de la década de 70.

Bajo este ideario llega el gobierno en el 1969 general Emílio Garrastazu Médici, tutelado por el Alto Mando de las Fuerzas Armadas, luego de un período de inestabilidad política desencadenada por la salida del entonces presidente, y también general, Artur daCosta e Silva, depuesto por motivos de salud y reemplazado por una Junta Militar. Contrariamente a la imagen austera de generales anteriores, Medici se presenta con una imagen suavizada, de hábitos simples y comunes. Esto contrasta con la austeridad implementada tanto en la acción política como económica.

Este período de gobierno recibió denominaciones muy distintas, cuando no opuestas entre sí: fueron llamados, al mismo tiempo, los años del "Milagro Brasilero", debido a la prosperidad económica que llevó a que Brasil se convirtiera en la décima economía del mundo, y también los "años de plomo", debido a la represión a los opositores al régimen que se tornó más intensa y violenta, conduciendo al encarcelamiento y muerte de muchos ciudadanos.

A parte de los temas políticos que predominaron en los titulares, la Folha de São Borja presentó en sus informes una diversidad de tópicos, como por ejemplo: cursos de memorización; desfiles de estudiantes; noticias policiales; filas para vacunarse, comparándolas con las de los autobuses en Porto Alegre; la organización de una fiesta en el Club Arte; el inicio del embelesamiento de la ciudad y notas cortas y variadas sobre la visita a la redacción del periódico, la transferencias de gerentes y directores de instituciones financieras, el horario de las farmacias y notas necrológicas; imprimiendo así una idea de normalidad en sus páginas semanales.

Se permiten incluso algunos temas direccionados al público femenino en tono humorístico, como por ejemplo el arte de bien vivir en casa o una receta para desquitarse, tema polémico en el periodo pues sugería que el ama de casa sirviera asados quemados y fuera descuidada con sus quehaceres domésticos y su apariencia. Se resalta en la categoría otros - temas correspondientes la inauguraciones de casas comerciales, festejos de graduación, cuestiones religiosas y de festejos religiosos, las que predominaron en el año 1972. Sin 
embargo lo más destacado son los asuntos relacionados al propio periódico Folha de São Borja: compra de nuevos equipamientos, cumpleaños o, incluso, la importancia del mismo.

\subsection{Recursos de legitimación del discurso de la Folha São Borja}

El universo discursivo del semanario utiliza las técnicas y prácticas propias del quehacer periodístico, vinculado a lo que Mouilloud (2002) señala como nombre-deperiódico, una producción impresa que guarda características de forma y contenido que se transformaron y se instituyeron a lo largo del tiempo. Así, el periódico toma para sí toda una carga de significación al presentarse frente a la comunidad el día 24 de febrero de 1970 con el status de periódico, o sea, se ocupa un espacio a partir del cual se ofrece a la comunidad una información - información periodística - que, más allá de las dificultades de conceptuación teórica, es un mensaje informativo que se confunde con el contexto debido a que es parte de "uma indústria produtora, na qual as decisões afloram de vago mecanismo, dirige-se a público vasto, de cujo repertório tem apenas ideias estatísticas; e se inocenta do que diz, como se falasse naturalmente dos fenômenos, sem nada ocultar, exagerar ou distorcer." (LAGE, 2001, p. 32)

El periódico se presenta a la comunidad como un medio de comunicación que presta un servicio a la comunidad, demostrando así su importancia, pero también refuerza la idea de un discurso competente, o sea, que está autorizado a decir lo que dice, sea porque recibió la información de la fuente oficial o por que pertenece al lugar en el que se hace conocer la realidad.

Desde este punto de vista se destaca una imagen de credibilidad, propia de quien se presenta como capaz de transmitir la verdad. Esa visión de cualificación y valorización se constituye por la adopción de una postura de seriedad, de responsabilidad y de pleno conocimiento de quién está transmitiendo el mensaje.

Este hacer búsqueda referencial en los procesos propios del periodismo, que según Mouillaud (2002) están referencialmente a servicio de la verdad. Para esto hay un pacto implícito con el lector cuya finalidad es hacer creer, y para ello se recurre al discurso del otro, o sea, la fuente, o "argumento da autoridade, que se fundamente na credibilidade do enunciador" (Mouillaud, 2002, p. 27).

En la Folha de São Borja se ha observado, a través del tipo de fuentes que utiliza y de la publicación de las cartas y opiniones del lector o de autoridades locales y regionales, que se busca resaltar la importancia del periódico para la comunidad. 
En lo referente a las fuentes de información, las mismas son siempre oficiales lo que implica, según Lage (2006), que son mantenidas por el Estado, o por instituciones que tengan algún poder de Estado o empresas y organizaciones, que recurren a las declaraciones para garantizar notoriedad. En el tratamiento de la relación con las fuentes oficiales por las cuales el periódico informa, se explicita la ocupación de puestos estratégicos por parte de los militares. Esto se debe a que, según Brum (2010), había en el periodo una centralidad en el poder del Estado, o sea,

os militares, além de assumirem postos no aparelho de Estado, foram contemplados também com cargos no comando diretivo das empresas estatais. Por essa via, aumentavam sua possibilidade de influência e controle, tanto político como econômico, sobre a sociedade. (BRUM, 2010, p. 304),

En los ejemplos a continuación valorizan la existencia misma del periódico, principalmente por el servicio que presta y por su alcance. Mostrando cómo el mismo es reivindicado tanto por personas de la comunidad, como por instituciones públicas, no sólo de la ciudad, sino también de otros municipios o, incluso, en otros países. Con ello, se refuerza la idea de la exhaustividad de la actividad local. Según destaca el propio periódico, las ediciones son leídas en Río de Janeiro y en Tokio. Como se ve en la figura a continuación: 


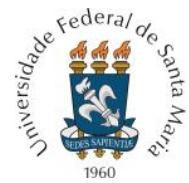

PROGRAMA DE PÓS-GRADUAÇÃO EM COMUNICAÇÃO DA UNIVERSIDADE FEDERAL DE SANTA MARIA

Figura 01 - Carta de lector del Rio de Janeiro - 00/05/1970

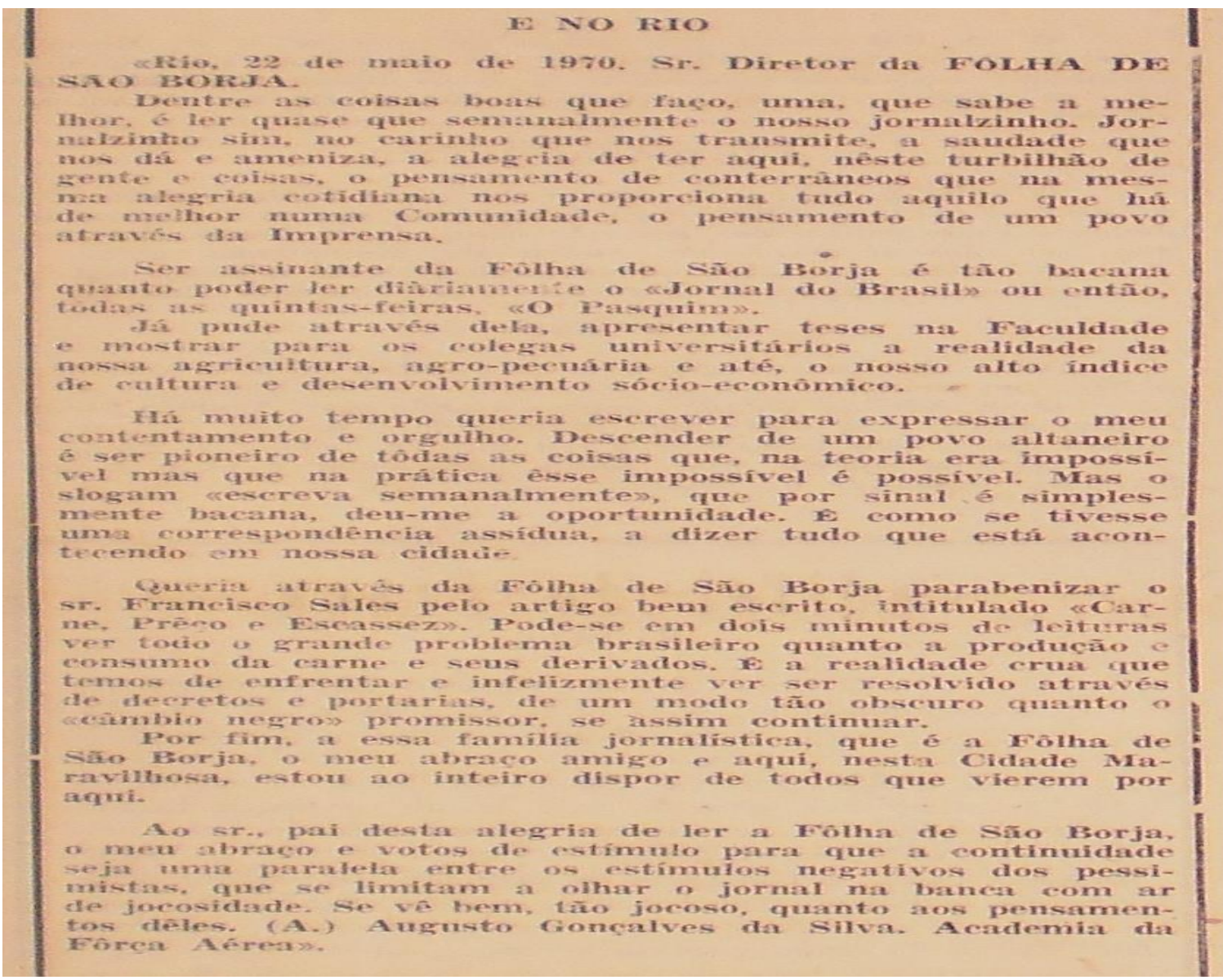

Fuente: archivo Folha de São Borja

En las palabras del lector publicadas por la Folha, se afirma la importancia de la circulación del periódico. Otros textos de carta del lector fueron divulgados en la portada del periódico y refuerzan la idea de proximidad.

Figura 02 - Folha de São Borja en Tóquio - 27/04/1971

\section{Fôlha de São Borja em Tóquio}

Mais uma vez registramos, ufanos,

exemplares da FOLHA DE SAO BORJA.

Ainda agora, mais uma demonstra

respeito às distâncias percorridas pelo nosso jornal. (das mais expressivas), tivemos com tamente da Capital do Japäo, da cidade jornal. Do outro lado do mundo - examundo (12 milhöes de habitantes), chegou à nossa redaça mais populosa cidade do to Cinte. Almada, da Varig em enegou à nossa redação um postal enviado peaqui em Tóquio, e através dela que êle diz «recebi uma FOLHA DE SẢO BORJA cumprimentos pela efeméride tăo significativa». $O$ aniversário da mesma. Os meus pônico no dia 18 dêste, e o selo lem caracteres japonêses) cartão foi pôsto no correio niventuais colecionadores desta cidade. Podem 


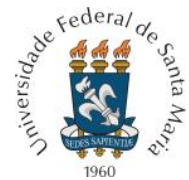

PROGRAMA DE PÓS-GRADUAÇÃO EM COMUNICAÇÃO DA UNIVERSIDADE FEDERAL DE SANTA MARIA

En el texto arriba, se destaca el alcance de las ediciones de la Folha de São Borja que llegan al Japón, sorprendiendo hasta a la misma redacción del Folha. Hay también una valorización y explicitación por parte del lector de un tipo periodismo en el que se "forma, agrada e informa", como se encuentra abajo:

Figura 03 - Folha de São Borja y el área del periodismo - 17/03/1970

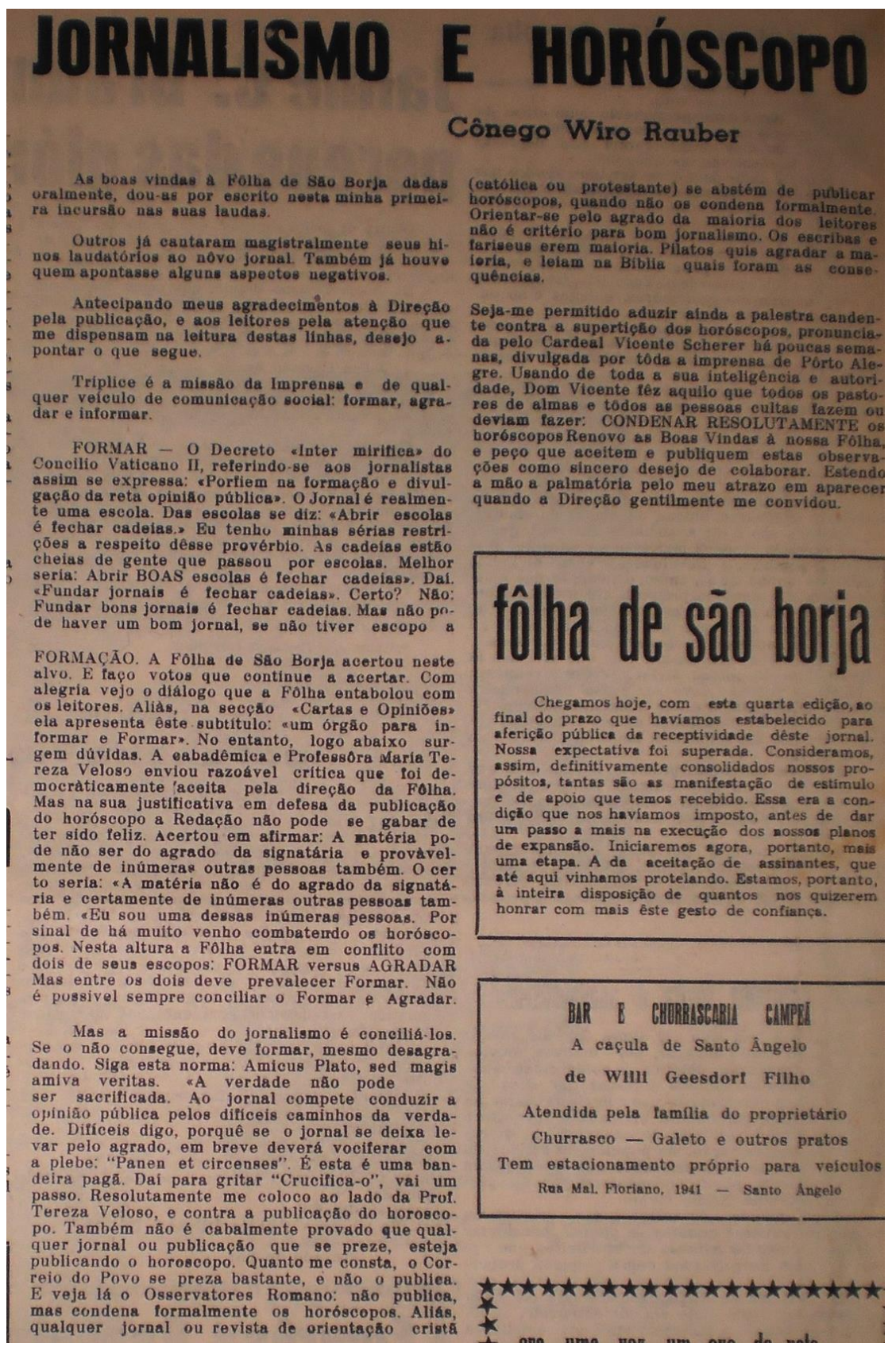

Fuente: archivo Folha de São Borja 
En ella el autor también afirma que la misión del periodismo es conciliar entre agradar y formar. Si esto se torna imposible, entonces debe formar porque "a verdade não pode ser sacrificada. Ao jornal compete conduzir a opinião pública pelos difíceis caminhos da verdade" (FSB, 1970). En la lectura del texto se entiende que es una opinión y que fue publicada a pedido. Sin embargo, el periódico no la señaliza como tal, dejando al lector el trabajo de entender se la política editorial del mismo es consistente o no con tal pensamiento, pues cuando no concordó con la opinión del lector, publicó la crítica, en la sección de cartas y opiniones y aún respondió algunos ítens relacionados a la práctica periodística que venía ejerciendo hasta entonces. A continuación el texto en cuestión:

Figura 04 - Folha de São Borja y la práctica de periodismo constituida - 10/03/197

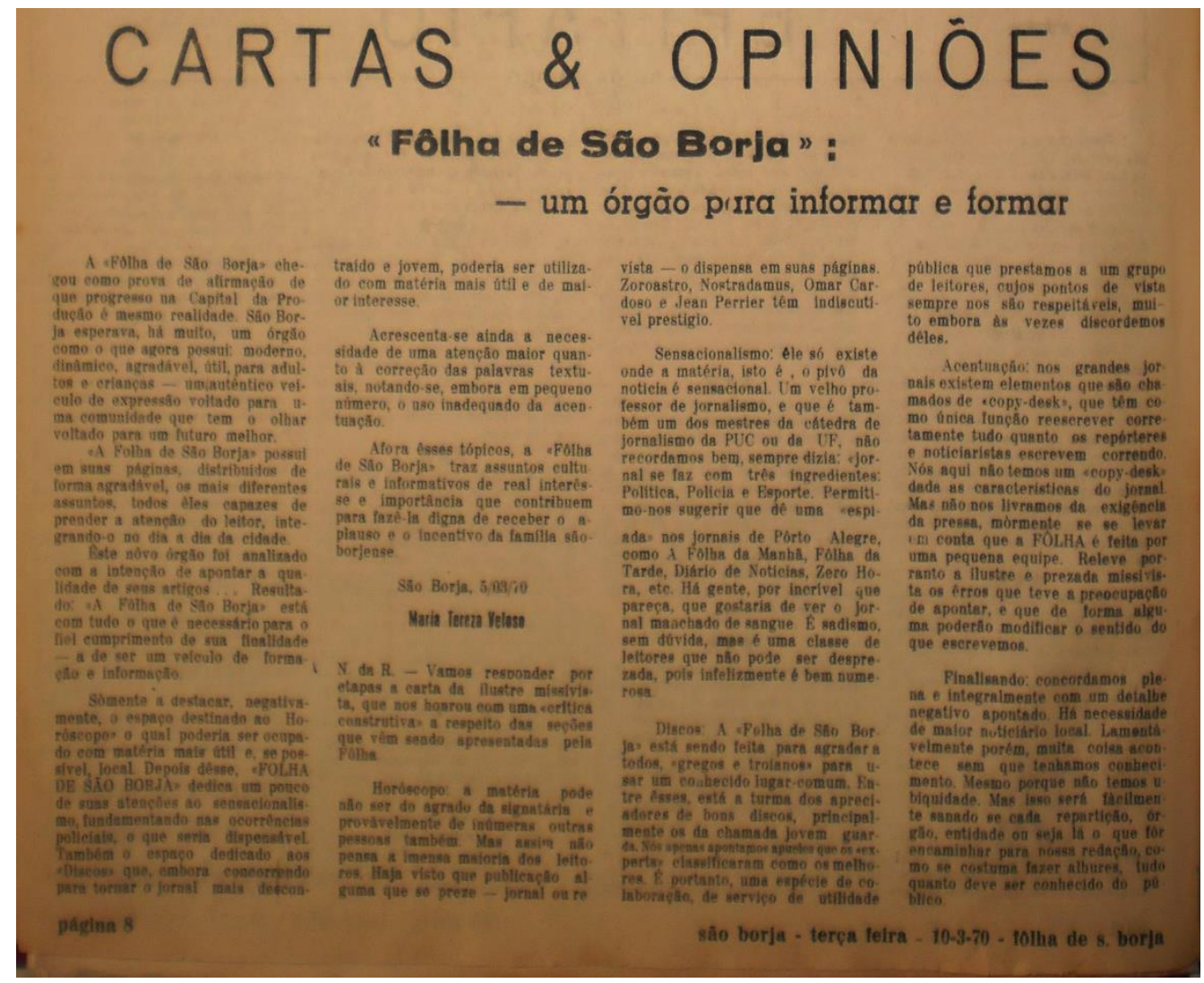

Fuente: archivo Folha de São Borja

La producción periodística de la Folha, de acuerdo a lo que se expresa en el texto anterior, seguía los ejemplos da Folha da Manhã y Folha da Tarde, ambos de São Paulo, Diário de Notícias, de Rio de Janeiro y Zero Hora, órgano de prensa de la capital gaucha. Es en este texto que el periódico también admite que debería traer más noticias locales. 
Reconociendo así explícitamente su orientación hacia las materias nacionales o regionales, e indicando que esto es en función "de que muitas coisas acontecem sem que tenhamos conhecimento. Mesmo porque não temos ubiquidade” (FSB, 1970). Afirman también que “esta situação poderia ser revertida se cada repartição, órgão ou seja lá o que for encaminhar para nossa redação como costuma fazer alhures tudo quanto deve ser conhecido do público" (FSB, 1970). De esa afirmación se deprende que el periodismo practicado en la empresa era pasivo, sin el trazo de la investigación o de la búsqueda de los hechos, quedando la merced de la comprensión de la fuente de información y de lo que la misma conocía, esperando que ello interesara a la comunidad y debiera ser divulgado.

La Folha manifestó que legitimaba este tipo de producción a través de la experiencia de los miembros de la empresa. En la figura abajo se tiene un ejemplo:

Figura 5 - Lector se manifiesta da Europa - 02/06/1970

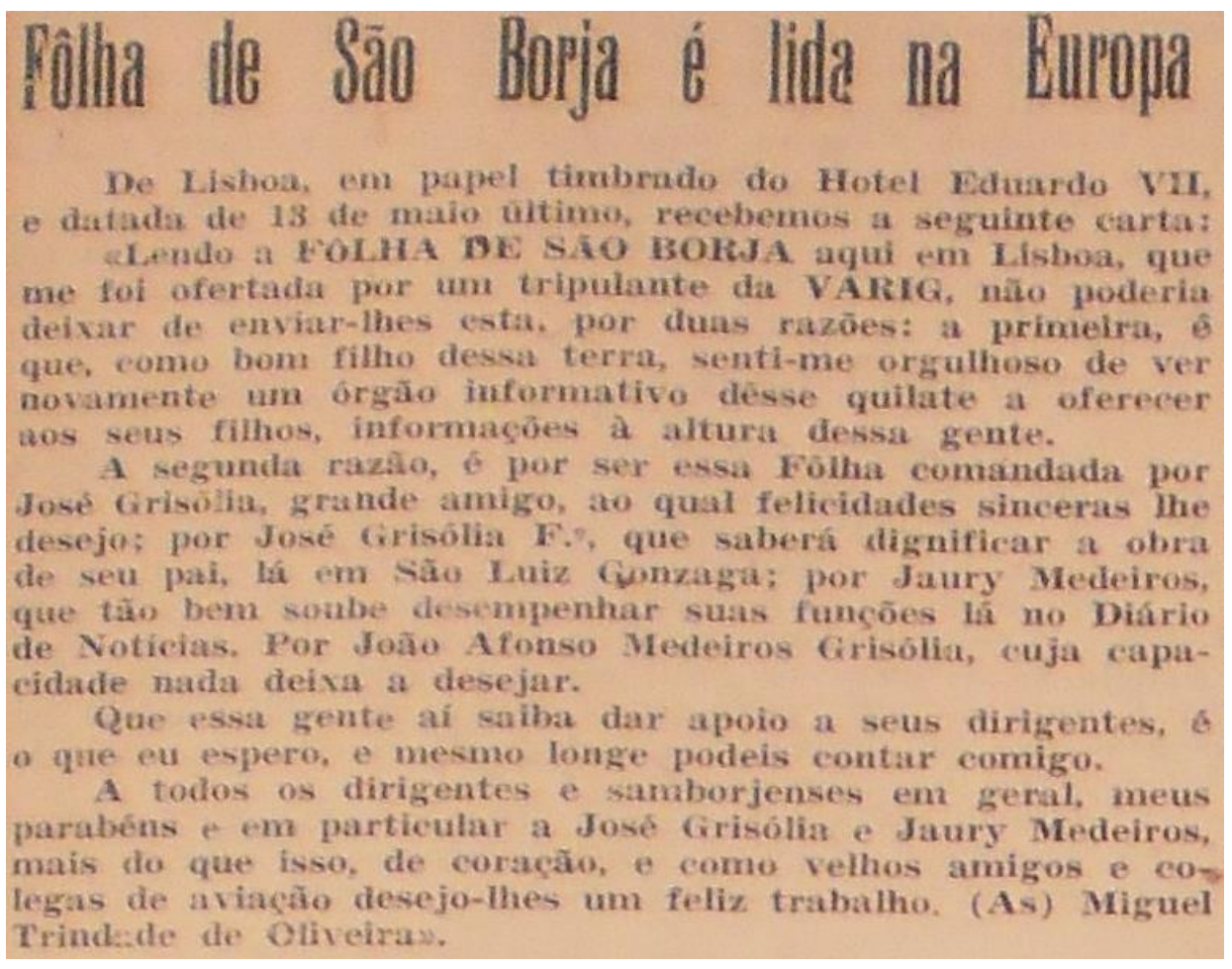

Fuente: archivo Folha de São Borja

El lector, autor del texto arriba, se manifestó destacando el nombre de los encargados de la empresa: la familia Grisólia. A Folha de São Borja tiene vínculos con la Gráfica $A$ Notícia, de São Luiz Gonzaga. Esta familia estaba caminando por lugares que ya otros habían recorrido, lo que le confería estatus y responsabilidad, como resalta el texto abajo (Figura 6), allí donde tantos otros fracasaron en la tarea de dar continuidad a los periódicos que fundaron. 
Figura 6 - texto de contratapa - 17/03/1970

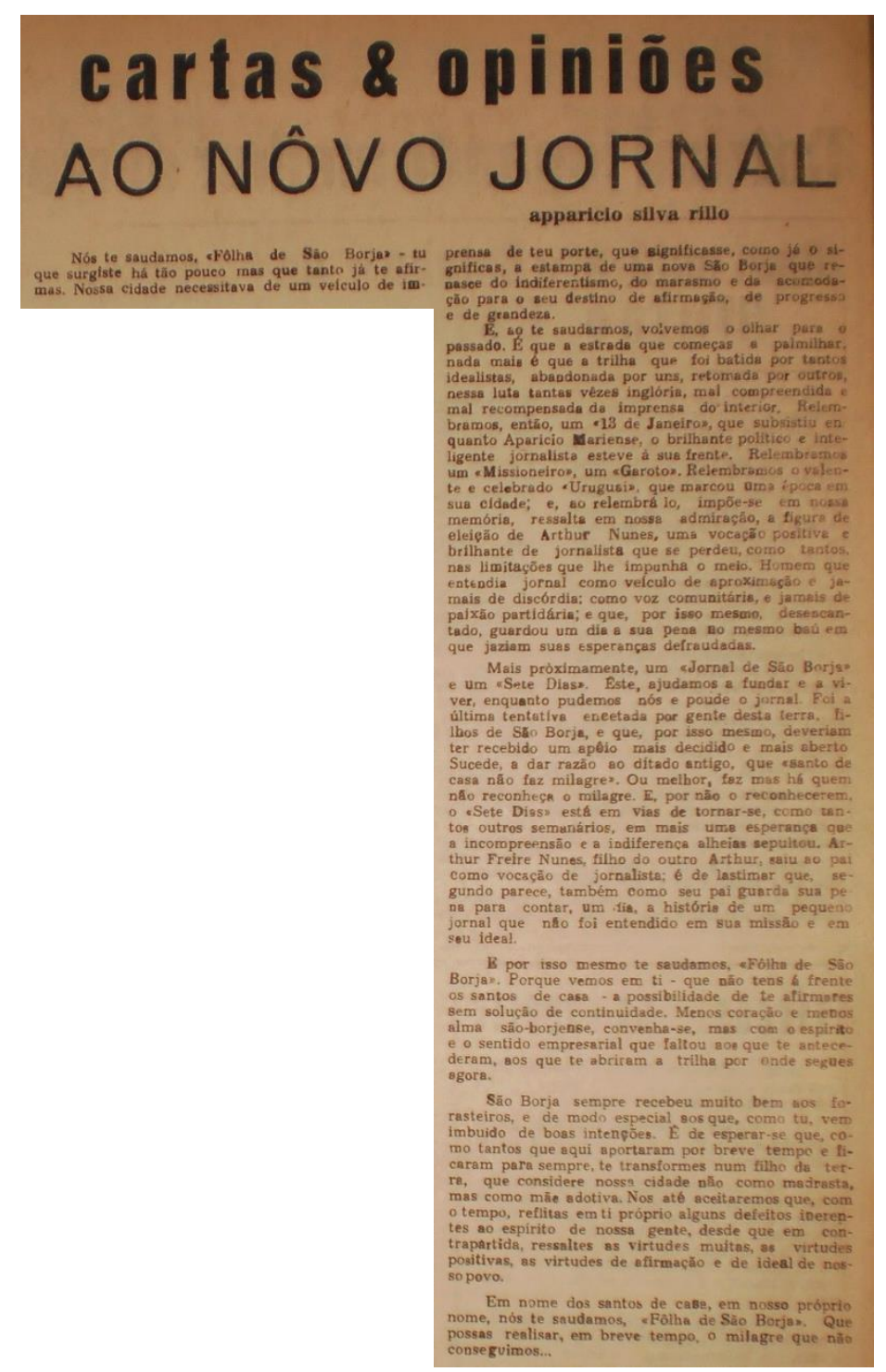

Fuente: archivo Folha de São Borja

En el caso de la Folha el escritor resalta que su sentido empresarial sería la razón que garantiza el éxito que otros no alcanzaron. También espera que el hecho de que la familia al frente de la empresa no sea de la ciudad, sea bien recibido visto que São Borja "sempre recebeu bem os forasteiros, e de modo especial, os que como tu vem imbuído de boas intensões" (FSB, 1970).

Además del discurso del lector, el semanario también destaca su repercusión en otros órganos de prensa de la propia comunidad o de la región. A continuación algunos ejemplos: 


\section{foi assim que a rádio frcnteira noticiou o nosso lançamento}

Contando o lançamento do primeiro aùmero de a FOLHA DE SAO BOKJA, OB nossos companteiros da Radio Fronteira do Sul levaram ao ar, no seu horário nobre, a seguinte nota que muito nos desvaneceu:

- Entroa hoje em nossa emissôra. allits vivamente eaperads, a primeira e-

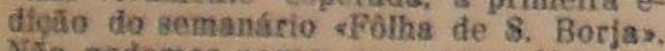
Náto podemos negar que aguardâvamos com viva impaciencia o surgir dêste nôyo companheiro de imprensa, pois era grande a nossa curiosidade para manusesrmos a primeiro numero desse jormal que esta fadado a contar com o carinho da familia samborfense.

Bonita em sua apresentaça, matérías de palpitante stualidade. leve e descontraida - a FOLHA DE SÄO BORIA passou de matos-em-míos pelo pessoal aqui da casa e de todos receber eloglos. $\mathrm{E}$ te fato um jornal bem tbolados e que certamente tomarâ rumos definitivos ns árdus missão da imprensa escrita. Para os homens que cultivam a terra e que nos dăo a alegria de nossa cidade ser a capital da produç̃o, nada foi esquecido. Um bonito trabalho sôbre o trigo e outro sôbre o arroz, contando a verdade sôbre a recente visita do presidente do Irga. Crônica policial, esportes, horóscopo, utilidades e vários outros enfoques que chamam a atençåo dos lei. tores.

Conhecendo, como conhecemos, o brilhante e dinamico jornalista Jaury Medeiros, chefe de redação, sabiamos que o fornal teria que ser prá-frente. Confirmou-se plenamente nossa previså.

Parabens a todos os homens que fazem a FOLHA DE S. BORJA e nossos votos para que o nôvo companheiro possa trihar rume certo, para o bem de nossa laboriosa gente.

Fuente: archivo Folha de São Borja

La manifestación de la Radio fue publicada de forma íntegra en la página interna del periódico y destacaba que la experiencia del periodista Jaury Medeiros garantizaba la calidad y la "bonita apresentação", "com matérias de palpitante atualidade". (FSB, 1970)

El surgimiento del periódico fue saludado por la prensa de Porto Alegre que destacó la importancia de los periódicos en el interior. 
Figura 8 - Mensaje de la Radio y TV difusora Canal 10 de Porto Alegre - 20/10/1970

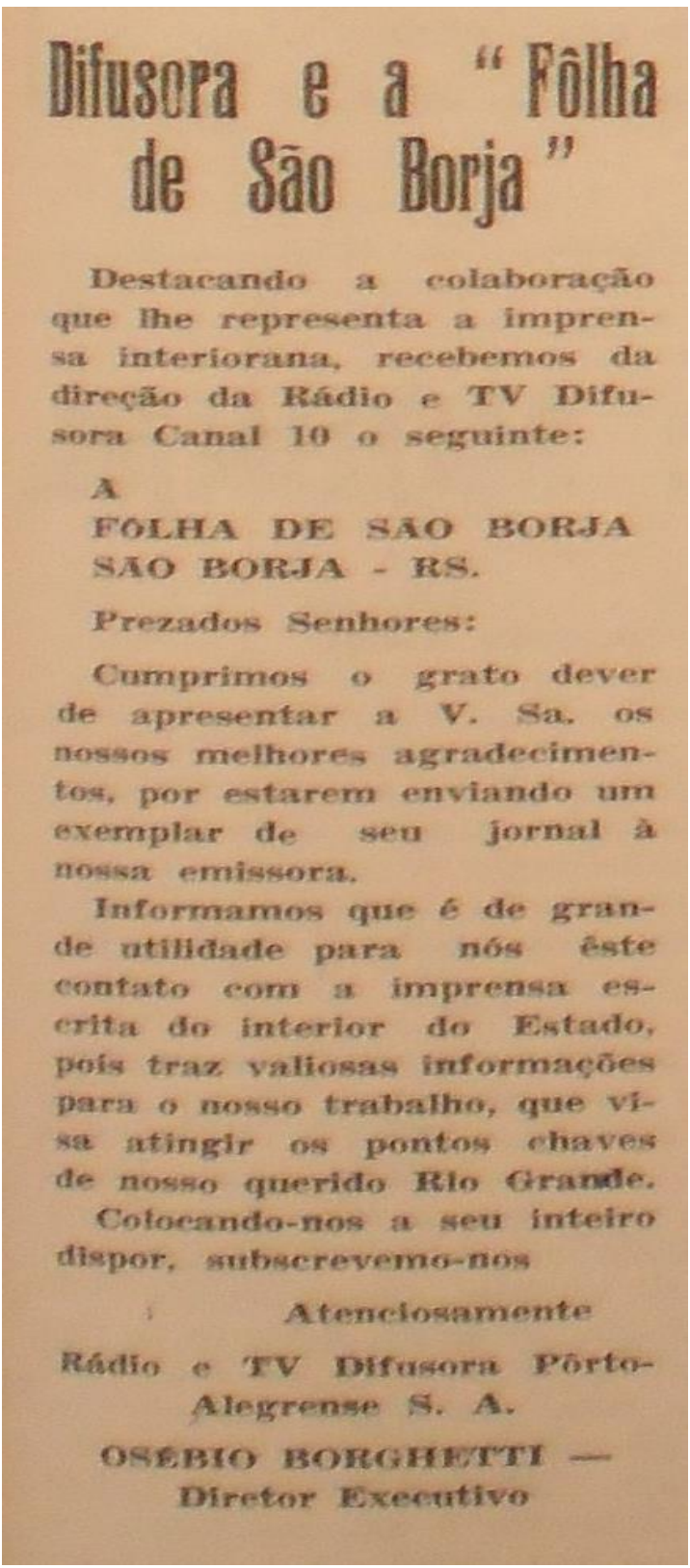

Fuente: archivo Folha de São Borja

El trabajo realizado por la Folha, según el texto arriba, trae valiosas informaciones. Ya la publicación Cinegrama, que era distribuida en los salas de cine de São Borja compara la fundación de un periódico con la instalación de un faro, pues ambos deben anunciar los peligros existentes y nortear rutas. Desea que la producción se inspire en Evaristo da Veiga o en Líbero Badaróiii, “inaudistas figuras do bom jornalismo” (FSB, 1970). 


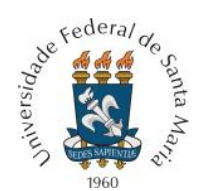

PROGRAMA DE PÓS-GRADUAÇÃO EM COMUNICAÇÃO DA UNIVERSIDADE FEDERAL DE SANTA MARIA

Figura 9 - Impreso Cinegrama - 07/04/1970

\section{cartas \& opiniões}

O CINEGRAMA SEMANAL, uma nova publicação que tem sua distribuição gratuita no recinto dos cinemas loeaes, contém em seu primeiro número a seguinte mał́ria sỏb e êste jornal:

\section{Palando Prabamente}

\section{Esereveu: SALVADOR MELU}

O povo local, esta de parabens com a circulação semanalmente de seu prestimoso órgão informativo A FOLHA DE SÃO BOFJA.

Fundar um jornallé instalar um farol.

Na verdade, qual é pcis, o destino de am farol?

Advertir sôbre um perigo iminente o navio que singra os mares, ou nortear-lhe a rota a seguir.

Grande é pois a responsabilidade que um jornal assume perante o público. Tem èle deveres que 0 inibem de descambar para o sensacionalismo. Tendo por conseguinte o grande galardão expressivo de ser o quarto podêr no mundo, a imprensa $\hat{\theta}$ a sentinela avançads, o flanco positivo e fiscalizador do poder público.

Que não se desdoire, que não feneça o entusiasmo e boa vontade dos diretores de A FOLHA DE SAO BuRJA, para gaudio da nossa gente. Que viva êste orgão informativo, agora e sempre através de seus responsaveis, inspirados nos exemplares de um Evaristo da Feiga ou de um Líbero Badaró, inaudi tas figuras do bom jornalismo.

Fuente: archivo Folha de São Borja

Además de la prensa hubo manifestaciones positivas por el surgimiento del periódico en la Cámara de concejales de la ciudad. A continuación se muestran dos ejemplos en los que el propio periódico informa las manifestaciones positivas en la casa legislativa: 
Figura 10 - Manifestación del concejal Ovídio Loureiro - 20/10/1970

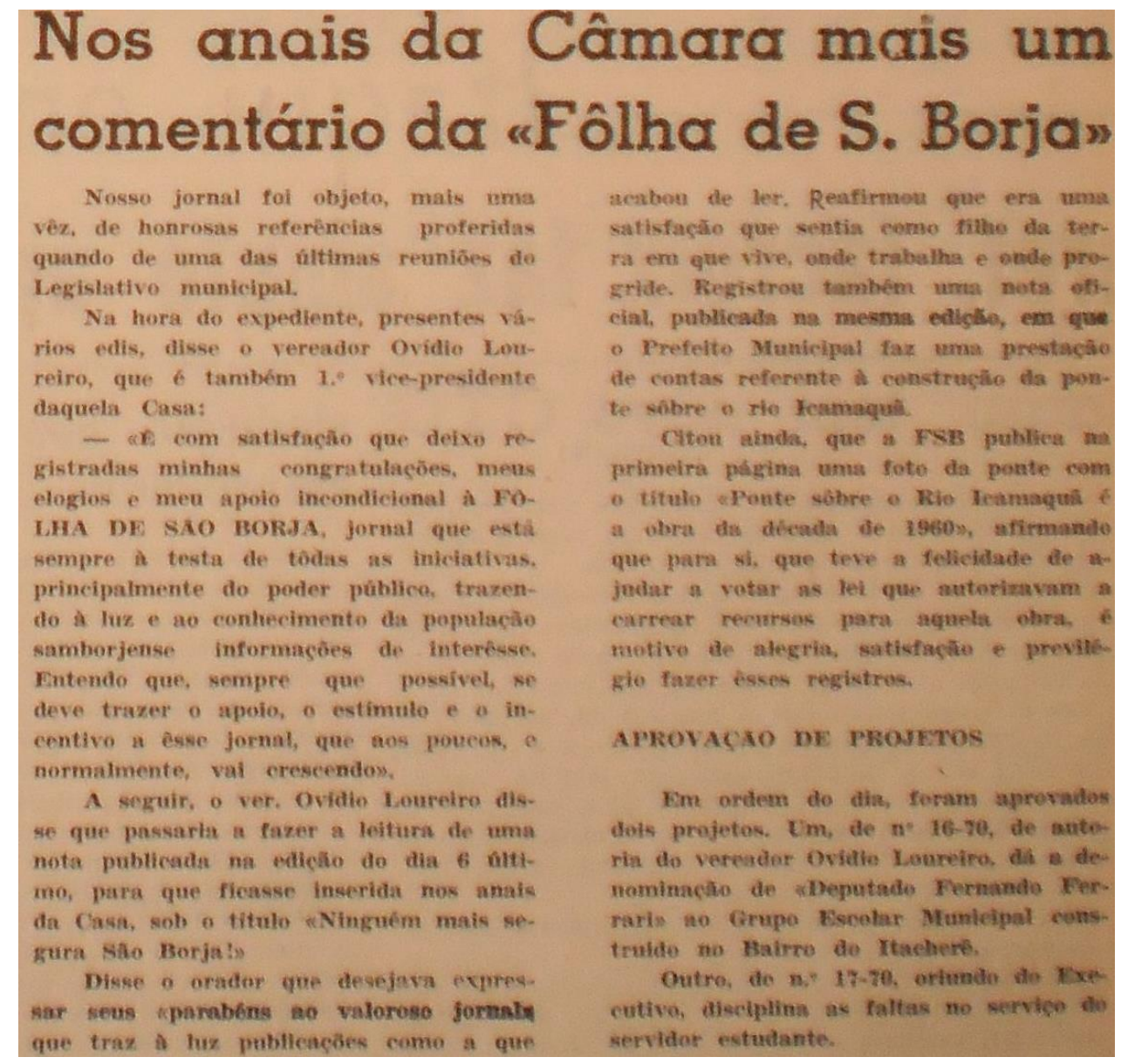

Fuente: archivo Folha de São Borja

El concejal manifiesta su apoyo y se destaca en la edición del periódico el artículo que trataba del desarrollo de São Borja, intitulado "Ninguém segura São Borja". El texto fue leído de forma íntegra para que formara parte de los anales de la institución.

Los tres elementos destacados a través de los ejemplos presentados anteriormente: (i) la utilización de las fuentes oficiales, (ii) las manifestaciones elogiosas por partes de los lectores y (iii) la publicación de las cartas que indican que La Folha de São Borja ha llegado a otros lugares rompiendo con el espacio geográfico local, permiten interpretar que el periódico refuerza su legitimación de actuación en:

- Primero: unirse a un discurso oficial - nacional desarrollista difundido pelo gobierno de la época - garante ventajas tanto a para la Folha como para el gobierno. Por un lado, el periódico indicaba las dificultades de producción asociadas a los costos monetarios elevados y 
la poca información disponible; por otro lado, para el gobierno la situación brindaba una ventana de oportunidad para colar la información que pretendía difundir, producida por su asesoría especial de relaciones públicas, sin filtros. Esta asociación entre actores afecta a los criterios de noticiabilidad, porque los mismo son construidos a partir del interés de las fuentes que organizan estrategias de ocupación de tiempo y espacio mediáticos, con lo que se pone a disposición de la audiencia un producto informativo excesivamente condicionado.

En relación a ello, Bermúdez (2006) señala que cuando esto ocurre no se cumple completamente la mediación debido a la dependencia de las fuentes que se relacionan con los intereses de terceros. Se fomenta así, según indica la autora, un periodismo de declaraciones, una práctica que favorece la difusión de las opiniones de las fuentes y que transmite la impresión de que el medio favorece a personajes públicos a través de entrevistas breves o declaraciones en comparecencias públicas a las que el protagonista sólo tiene que responder, sin más objeciones. Así, para Bermúdez (2006) la noticia queda condicionada no solamente a su estructura de construcción discursiva, sino también a las necesidades, carencias e inclinaciones políticas del propio medio, como empresa y como agente social. La organización de la redacción, las rutinas productivas, las fuentes, la ideología del medio, los intereses de éste como empresa y la dependencia económica, repercuten sobre la confección del temario. Ese rasgo permite comprender que la noticia estaba condicionada al armado de la agenda temática nacional, y cuando no trataba del desarrollo económico o de la política, tenía un carácter más factual relacionado a aquello que era accesible por el periódico, como por ejemplo la vista de una autoridad, la realización del desfile conmemorativo, la acción del gobernante local.

- Segundo, la valorización de la existencia del periódico y de su continuidad consolida en la comunidad la actuación de la Familia Grisólia en la ciudad y región. Esto elemento de poder es utilizado para colocar al periódico al mismo nivel de la prensa nacional, que en aquel momento estaba se expandiendo. A continuación se muestran ejemplos que corroboran la actuación de la familia Grisólia en la prensa. Se destaca que los artículos son de producción própria, indicando un discurso de autovaloración. En el artículo de la figura 11, se destaca que el propietario de la Folha, era el vicepresidente de la Rede Missioneira Jornal, compuesta por los periódicos: A notícia, Folha de São Borja y Folha de Santiago. El texto resalta que por ocupar dicho cargo, el propietario de la Folha viajó a Europa para participar de la Feria Internacional de Artes Gráficas, en Alemania. El viaje tenía como objetivo conocer la 


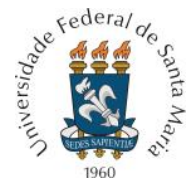

PROGRAMA DE PÓS-GRADUAÇÃO EM COMUNICAÇÃO DA UNIVERSIDADE FEDERAL DE SANTA MARIA

moderna maquinaria a disposición para esta área y su adquisición para la confección de la Folha de São Borja.

Figura 11 - Familia Grisólia - experiencia en la prensa - 30/05/1972

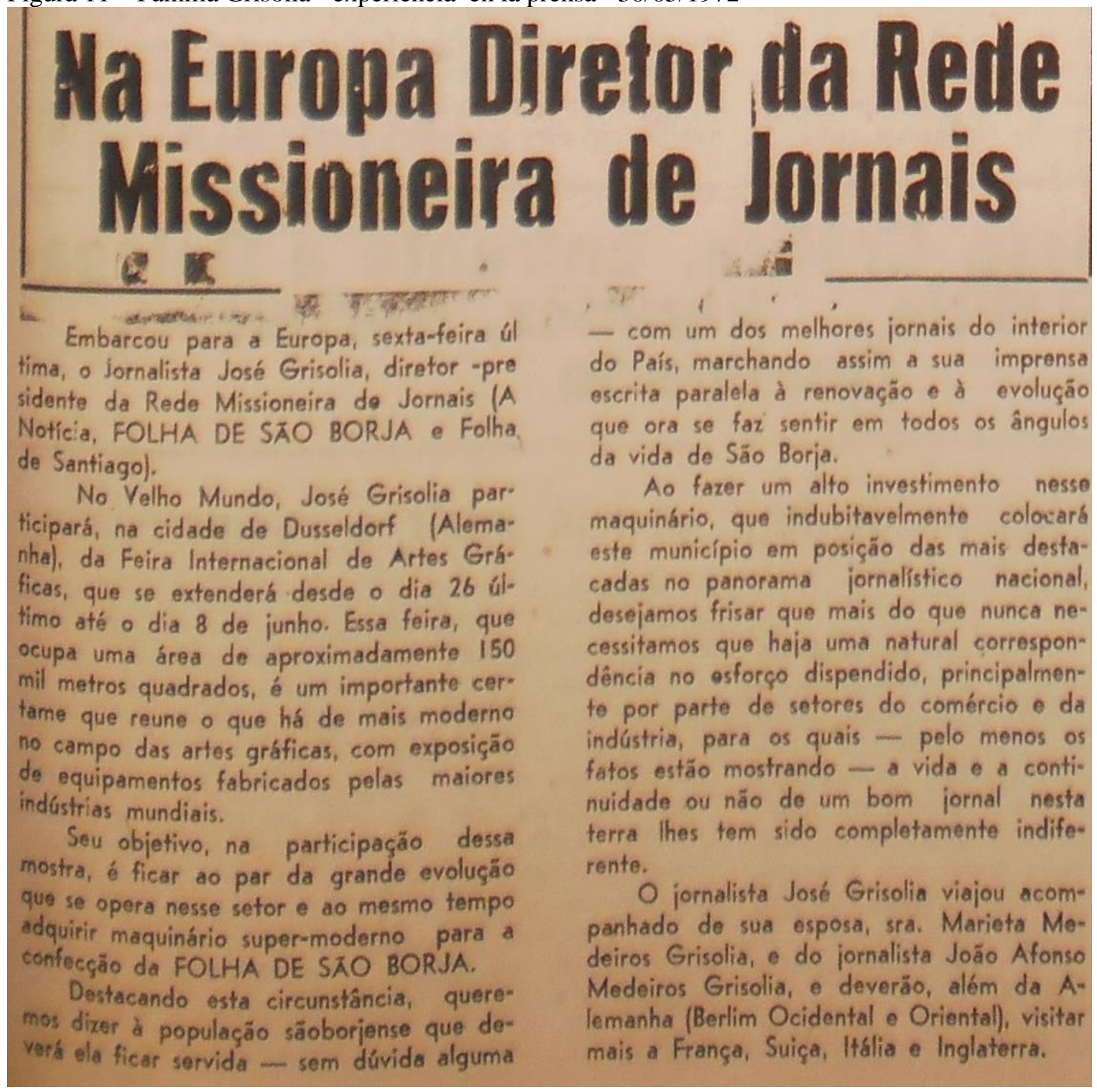

Fuente: archivo Folha de São Borja

En el texto a continuación, se destaca que la Familia Grisólia estuvo vinculada con la adquisición de la gráfica de la editora A Platéia para la "Rede Fronteira-Missões de Jornais". 
Figura 12- "Rede Fronteira-Missões de Jornais" - 06/03/1973

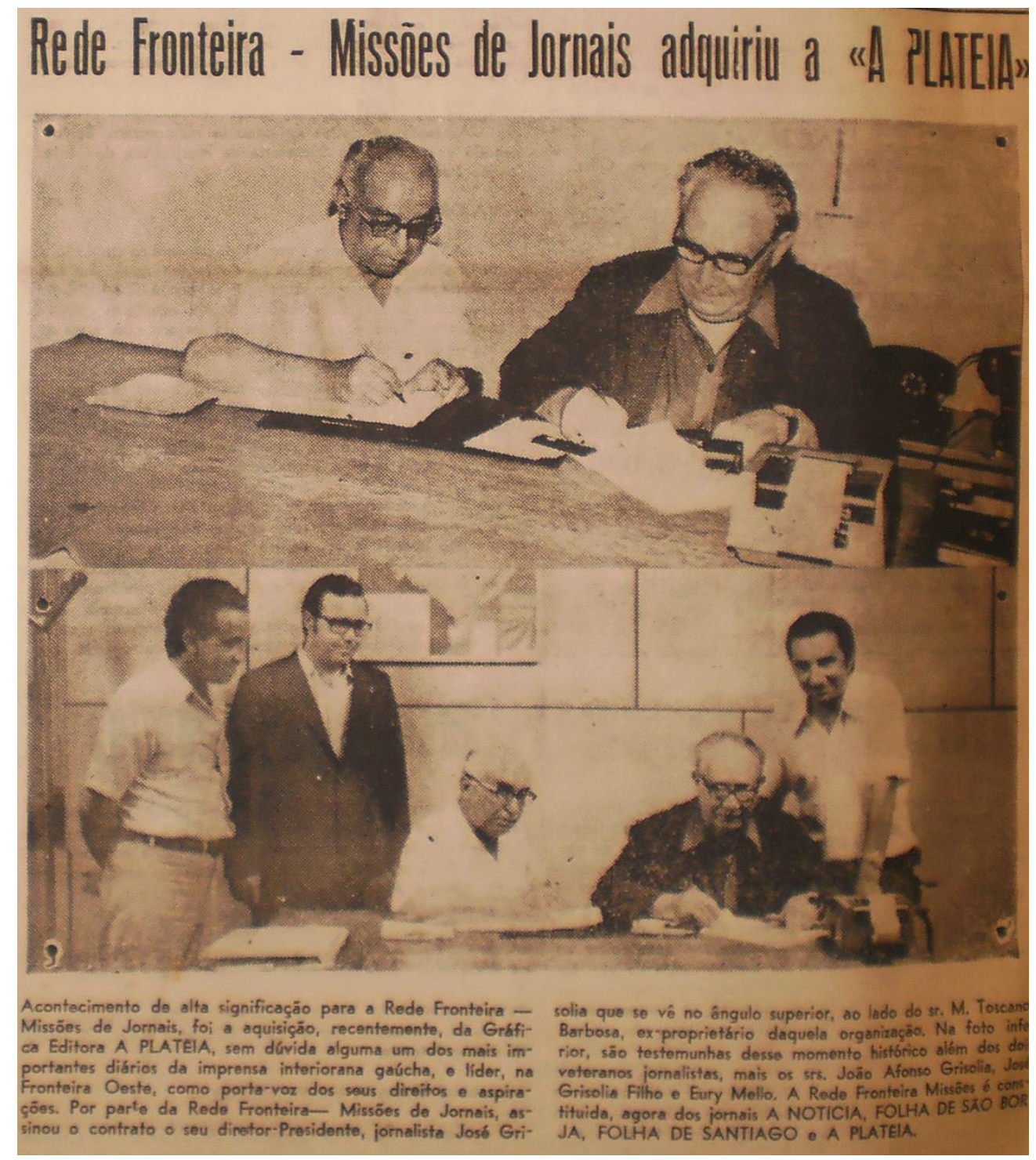

Fuente: archivo Folha de São Borja

En las fotografías se muestra a José Grisólia, João Afonso Grisólia, José Grisólia Filho y Eury Mello, todos integrantes de la dirección de la Folha de São Borja.

También se destacaron las opiniones positivas del legislador Loureiro con motivo de la decisión del propietario de la Folha de São Borja, José Gisólia, de instalar en la ciudad la Gráfica A Noticia, previamente ubicada en la ciudad de São Luiz Gonzaga. En el pronunciamiento, publicado completo en el periódico, el concejal destaca la contribución de la empresa de la Familia Grisólia para el progreso de São Borja al instalar la gráfica y que "a Folha de São Borja, que tão relevantes serviços tem prestado à nossa comunidade, passará a ser editada aqui, [...] para tornar-se um grande jornal (...)" (FSB, 1972) 
- El tercer punto, se relaciona con la idea de proximidad, una proximidad que no es geográfica sino psicológica y social y está configurada en torno a los informes nacionales que, llegan a cualquiera parte del mundo, y proporcionan un sentido de unidad e integración nacional. Esto se observa no solo en las publicaciones de cartas de los lectores anunciando que el periódico llego a distintas partes del mundo, también cunado se analiza las temáticas de las noticia y se verifica un alineamiento del discurso de la Folha de São Borja con el ideario de desarrollo y seguridad difundida por el gobierno militar. Al vincular su discurso al del gobierno nacional el periódico desplazó la proximidad geográfica hacia la dimensión psicológica y social. Los acontecimientos presentados en el periódico pierden la relación de prójimo y de distante que los separa territorialmente. Los artículos de la Folha pertenecen a ese territorio, donde se colocan a nivel nacional y se proyecta a São Borja el mismo status, el periódico toma la parte por el todo: la ciudad y su desempeño político, social y económico, como representativo del país.

Según Cerri (2002, p. 1), lo que llama uso de las ideologías geográficas del régimen militar, así como su nacionalismo en general, puede ser comprendido también como una herramienta de ajustamiento social, pues refuerza el sentimiento de pertenecer a una nación que puede no ser necesariamente donde se ha nacido o donde se esté en aquel momento, porque ese lugar "é, genericamente, o Brasil. [...] Sua compensação imaginária é pertencer a um Estado-nação [...]”

De esta manera, el periódico legitima su discurso ante el tema: presume de su comunidad local, resaltando la importancia de su inserción nacional ambos y en el en cuanto periodística círculos políticos; y el gobierno militar actuando como la voz del lugar ideal político-económico y socio-culturales formateado por la desarrollista nacional ideología que desde 1964 estaba en proceso de ejecución en el país.

\section{CONSIDERACIONES FINALES}

Desde esto se apunta que en la Folha de São Borja no hay una distinción entre la esfera local y la nacional, porque para el periódico la ciudad de São Borja tenía una importancia y una proximidad con las autoridades y personajes nacionales que la colocaban en posición céntrica de atención, principalmente por el énfasis que se da a la cuestión económica, identificando el municipio como la capital de la producción. 
También se resalta que el informativo al destacar la ciudad, lo hace como si el semanario tuviera un alcance y una circulación nacional. Así se explica que los hechos locales tengan relación con el ámbito nacional, porque se considera São Borja como Brasil en escala más pequeña y que se encuentra reproducido en los atributos del país.

Esa discusión está relacionada al periodismo, porque la producción del mismo es una forma simbólica que a lo largo del desarrollo de los medios comunicacionales adquirió status de bien simbólico, o sea, producto que por ser apreciado o depreciado posee valor simbólico y por esto se atribuye un valor económico, lo que confiere al periódico una posición ambigua frente a la sociedad: por un lado sirve a los intereses público y por otro al capital privado. Lage (2001) ya anunciaba que la primera cosa que un periódico informa es su ideología. En un diario grande, será del segmento económico, en uno pequeño estará las familias y grupos influentes en la ciudad.

Además es característico de la evolución histórica del periodismo en Brasil una adherencia al poder político que tuteló, benefició o financió, muchos periódicos impresos en el país, principalmente, en el Brasil colonial, periodo en que factores como la organización social-económica, el analfabetismo, la ausencia de urbanización, la organización política basada en una burocracia estatal e incluso la censura y obscurantismo de la metrópoli portuguesa, dificultaron la implementación de una prensa autónoma, que requiere como respaldo de la libertad de prensa instituciones políticas y sociales democráticas y avanzadas, como las que se encontraban en algunos países de Europa en aquella época. Un ejemplo emblemático deste proceso es Gazeta do Rio de Janeiro, primer periódico brasileño, produzido en território nacional que según Romancini \& Lago (2007, p. 42), "proclamava-se não oficial, mas era certamente oficioso, pouco voltado à crítica e à realidade local."

Romancini \& Lago (2007) señalan que hubo un cambio lento en el hacer periodístico, más por cuestiones económicas de que políticas. Sí había libertad, pero no desarrollo económico. La prensa se hacía gran empresa, optimizada por la coyuntura favorable, que encontró en el periodismo el ensayo ideal para nuevas relaciones de mercado del sector. El periodismo por este desarrollo puede ser comprendido como un proceso social y de un hacer con intenciones, que están necesariamente vinculadas a los motivos éticos, como indica Chaparro (2008), que serían la viabilización del acceso y ejercicio del derecho a la información. 
Sin embargo en periodos de excepción ese es uno de los primeros derechos a ser atacado. Traquina (2005) ya cuestionaba si existía la posibilidad de hacer periodismo en tiempos de autoritarismo. Para él hay una incompatibilidad para la convivencia harmoniosa de esos dos elementos, porque en su esencia la libertad del periodismo está directamente relacionada a la disminución del poder del gobernante. Hay una relación inversa de proporcionalidad: cuánto mayor la libertad, menor el poder y viceversa. Cuando coexisten sin conflictos, el periodismo tiende a sucumbir en su función social, pues se transforma en propaganda a servicio del poder vigente. Traquina (2005) entiende que existe una relación adversarial de naturaleza definidora de funciones entre el periodismo y el poder. Incluso en las democracias más estables, la libertad, defendida por el periodismo, es un valor que debería estar por encima de todos los otros.

\section{REFERÊNCIAS}

ABREU, A. A mídia na transição democrática brasileira. Sociologia, Problemas e Práticas, n. ${ }^{\circ}$ 48, pp. 53-65, 2005.

ABREU, J. As manobras da informação: análise da cobertura jornalística da luta armada no Brasil (1965-1979). Niterói: UFF, 2000.

AGUIAR. C. Mídia e autoritarismo no Brasil Pós-64: a propósito de continuidades e rupturas. Revista Comunicação: Veredas Ano III - N 03. 2004.

ALMEIDA, A. A ditadura dos generais. 2. Ed. Rio de Janeiro: Bertrand, 2007.

ALSINA. M. La construcción de la noticia. 2. ed. Barcelona: Paidós, 1993.

ALVES, M. Estado e oposição no Brasil. 2.ed. Petrópolis: Vozes, 1992.

AQUINO, M. Censura, imprensa, Estado autoritário (1968-1978). Bauru: Edusc, 1999.

BIROLI, F. João Goulart e o golpe de 1964 na imprensa, da transição aos dias atuais: uma análise das relações entre mídia, política e memória. Anais do I Congresso Anual da Associação Brasileira de Pesquisadores de Comunicação e Política, ocorrido na Universidade Federal da Bahia Salvador-BA. 2006. Disponível em http://www.compolitica.org/home/wpcontent/uploads/2010/11/Biroli_2006.pdf.

BERGER, P. \& Luckmann, T. A construção social da realidade. Rio de Janeiro: Editora Vozes, 1999.

BERMÚDEZ, M. Los medios toman partido. ÁMBITOS. N $N^{\circ} 15,2006$ - disponível em http://grupo.us.es/grehcco/ambitos\%2015/15vazquez.pdf acesso em: 22/10/2011.

CAMPONEZ, C. Jornalismo de proximidade - Rituais de comunicação na imprensa regional. Coimbra: Minerva, 2002. 
CARDOSO, F. (1975). Autoritarismo e Democratização. 2. ed, Rio de Janeiro: Paz e Terra.

CERRI, L. Ensino de História e Nação na Propaganda do "Milagre Econômico. Revista brasileira de História vol.22 no.43 São Paulo, 2002.

CHAPARRO, M. Sotaques D'Aquem E D'Alem Mar: Travessias Para Uma Nova Teoria de Generos Jornalisticos. São Paulo: Summus, 2007.

COLLIER, D. (org.) O Novo Autoritarismo na América Latina. Rio de Janeiro: Paz e terra, 1982.

CORREIA, J. Jornalismo Regional e Cidadania. Acesso em 25/06/2010. 2010. Disponível em Biblioteca On-line de Ciências da Comunicação da Universidade da Beira Interior: http://bocc.ubi.pt.

DORNELLES. B. Jornalimo interiorano. Acesso em 20/07/2010. 2010. Disponível em Biblioteca On-line de Ciências da Comunicação da Universidade da Beira Interior: http://bocc.ubi.pt. Jornalismo solidário. Porto Alegre: GCI, 2006.

EMERIM, C. \& PIPPI, J. Memória sobre a imprensa em São Borja. Santa Maria: Editora da UFSM, 2007

FIORIN, J. O Regime de 1964 - Discurso e Ideologia. São Paulo: Atual, 1988.

FONTCUBERTA, M. La Noticia - Pistas para percibir el mundo. Barcelona: Paidós, 1993.

GASPARI, E. A Ditadura Envergonhada. Vol 1. Coleção As Ilusões Armadas, São Paulo: Companhia da Letras, 2002.

LAGE, N. Ideologia e Técnica da Noticia 3a.. ed. Florianópolis: Insular-Edufsc , 2001

Estrutura da notícia. 5. ed. São Paulo: Ática, 1999. (Série Princípios)

Linguagem Jornalística. 2.ed. São Paulo: Ática, 1986.

MACHADO, A. Mídia e política de identidade: a malha decomunicação local-internacional nas fronteiras brasileiras. Ano IX - ${ }^{\circ} 10$ - Outubro, 2008.

MOUILLAUD, M. Da forma ao Sentido. In: Porto, S. O jornal: da forma ao sentido. Brasília: UNB, 2002.

O’DONNELL, G. Contrapontos: autoritarismo e democratização. São Paulo: vértice, 1986.

ROMANCINI, R. \& LAGO, C. História do Jornalismo no Brasil. Florianópolis: Insular, 2007.

SKIDMORE, T. Brasil: de Castelo a Tancredo. 4.ed. Rio de Janeiro: Paz e Terra. 1988.

TÉTU, J. A informação local: espaço público local e suas mediações. In. Porto, S. O jornal: da forma ao sentido. Brasília: UNB, 2002.

TRAQUINA, N. As notícias. Revista da Comunicação e Linguagens. Lisboa/Portugal, no. 8, 1988. 
Possui graduação em Comunicação Social Jornalismo pela Universidade Federal de Santa Maria (1995) e mestrado em Ciências Sociais pela Universidade do Vale do Rio dos Sinos (2005). Doutorado em Ciências Sociais pela Faculdad Latinoamericana de Ciencias Sociales, (sede Argentina). Professora adjunto III na Universidade Federal do Pampa - Unipampa, curso de jornalismo. Pesquisadora em comunicação e política com ênfase em história da mídia - jornalismo impresso ditadura militar, memória e fronteira.

Esta obra está licenciada sob uma Licença Creative Commons.

\begin{abstract}
' Esta discusión está articulada a partir de la tesis intitula "Periodismo y autoritarismo: ideología e relaciones de poder en el discurso de la Folha de São Borja en el periodo de los años 70 a 73 en la frontera oeste del río grande del sur", desarrollada en la Faculdad Latinoamericana de Ciencias Sociales, sede Argentina, en que se investiga la ideología y las relaciones de poder en el periodismo impreso producido en la frontera oeste del Río Grande del Sur en la década de 70.
\end{abstract}

ii Datos conforme Núcleo regional de integración de la franja de frontera - gobierno del Estado del Río Grande del Sur - Plano de desarrollo e integración de la franja de frontera del estado del río grande del sur - pdif rs Porto Alegre - 2012.

iii Libero Badaró y Evarito da Veiga dos periodistas y políticos que actuaron en Brasil el siglo XIX. Badaró, defensor del liberalismo, fundó y redactaba el periódico "El Observador Constitucional", surgido en 1829, impreso en la tipografía "O Farol Paulistano, a principio, bajo la dirección exclusiva de Líbero Badaró. El periódico era liberal, pero de cara moderada, como el que Evaristo de la Veiga imprimía en Río de Janeiro, la Aurora Fluminense (1827). Este de oposición al gobierno, fue difusor de ideas constitucionalistas y liberales. Ambos alcanzaron gran éxito en sus publicaciones lo que les rindió las enemistadas de los absolutistas. 